\title{
Routine Use of the Scribner Shunt for Haemodialysis
}

\author{
P. B. CLARK,* M.D., M.CHIR., F.R.C.S. ; F. M. PARSONS, † M.D., B.SC., M.R.C.P.ED.
}

Brit. med. F., 1966, 1, 1200-1202

The Scribner shunt (Quinton, Dillard, Cole, and Scribner, 1962) (Fig. 1) is an artificial arteriovenous fistula made of inert plastic tubing which is used for repeated haemodialysis. When dialysis is required the U-tube connecting the arterial and venous limbs of the shunt is removed and the patient is connected to the dialyser. At the end of dialysis the U-tube is replaced.

The use of the Scribner shunt in intermittent haemodialysis for chronic renal failure is well recognized, and Chisholm (1961) has advocated its use in some patients with acute renal failure and especially those who have few available veins. It is our belief that it should be used in all patients with acute renal failure who are likely to require more than one haemodialysis; certain patients with acute renal failure may be alternatively managed successfully by peritoneal dialysis.

It is the purpose of this paper to show that the routine use of the Scribner shunt, as opposed to repeated cannulation, saves time and trouble in a busy artificial kidney unit and increases the safety of dialysis. Now that all parts of this shunt are manufactured in Great Britain the increase in cost is not significant. Improvements in the technique of inserting the shunt, the experience of the first year, and the complications encountered are also outlined.

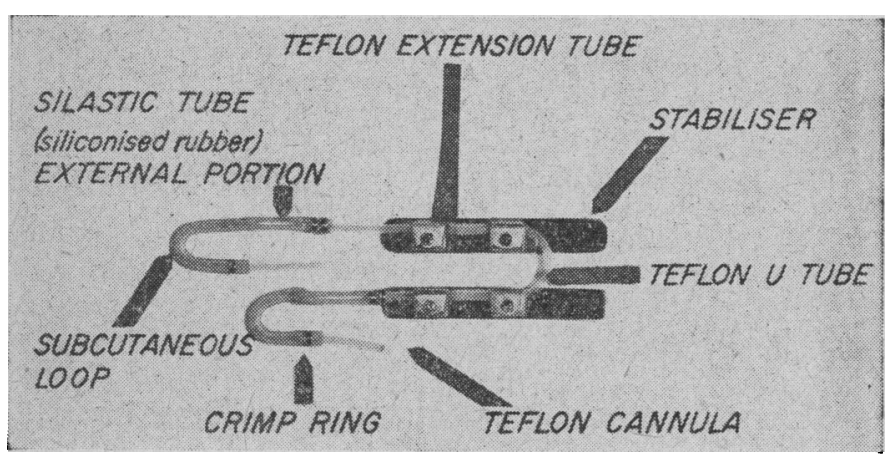

Fig. 1.-The Scribner shunt.

\section{Material}

The Scribner shunt has been used in Leeds since November 1963. An analysis of the methods of cannulation used for dialysis during this year is given in Table $I$.

Of a total of 49 shunts inserted, three could not be used because of early clotting, and one moribund patient died after

TABLB I.-Method of Cannulation and Number of Haemodialyses

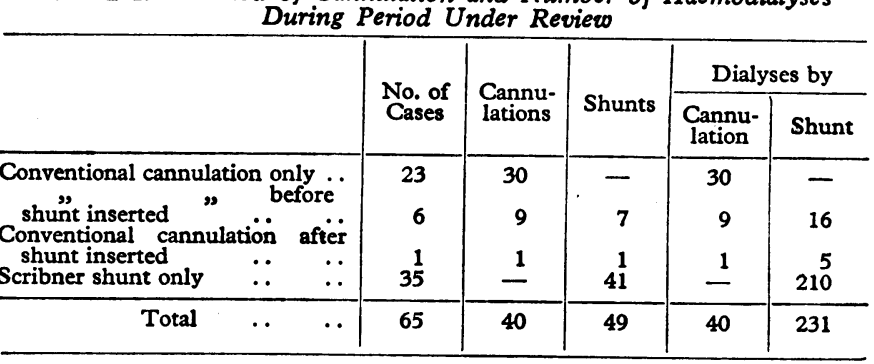

the shunt had been inserted and before she could be dialysed. The shunts were inserted at the wrist in 39 patients (on the left in 27), at the ankle in eight, and just below the elbow in two.

After the first four months, when the full advantages of the Scribner shunt had been realized, all patients were treated either by a single cannulation for one dialysis or by the immediate insertion of a shunt for repeated dialysis. The increasing use of the Scribner shunt for dialysis as opposed to conventional cannulation during this first year is shown in Fig. 2.

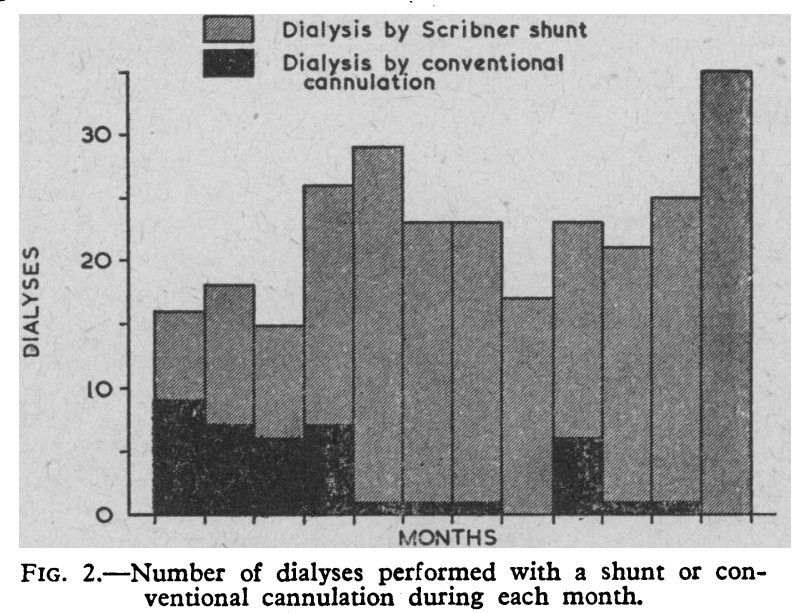

Six patients were being treated by intermittent haemodialysis while awaiting transplantation; they had a total of 118 dialyses. The remaining patients, it is believed, would have been dialysed in any artificial-kidney unit. The indications for dialysis in these patients are listed in Table II. This table also shows if single or repeated dialysis was required and the method of cannulation used.

TABLE II.-Indications for Dialysis and Number of Patients Treated

\begin{tabular}{|c|c|c|c|c|c|c|}
\hline & \multicolumn{3}{|c|}{ Conventional Cannulation } & \multicolumn{3}{|c|}{ Scribner Shunt } \\
\hline & \multicolumn{2}{|c|}{ Dialyses } & \multirow{2}{*}{ Total } & \multicolumn{2}{|c|}{ Dialyses } & \multirow{2}{*}{ Total } \\
\hline & 1 & $>1$ & & 1 & $>1$ & \\
\hline $\begin{array}{l}\text { Acute renal failure .. } \\
\text { Barbiturate poisoning } \\
\text { Diagnosis unknown initially } \\
\text { Chronic renal failure: } \\
\text { Acute exacerbation } \\
\begin{array}{l}\text { Pre-operative } \quad . . \\
\text {. . . }\end{array}\end{array}$ & $\begin{array}{l}6 \\
3 \\
4 \\
1 \\
5\end{array}$ & $\begin{array}{l}\frac{2}{1} \\
\frac{1}{1}\end{array}$ & $\begin{array}{l}8 \\
3 \\
5 \\
1 \\
6\end{array}$ & $\begin{array}{l}\frac{6}{2} \\
1 \\
1\end{array}$ & $\begin{array}{l}\frac{20}{3} \\
\frac{2}{-}\end{array}$ & $\begin{array}{c}\frac{26}{6 *} \\
3 \\
1\end{array}$ \\
\hline $\begin{array}{c}\text { Total } \\
\text { Chronic renal failure-for } \\
\text { transplantation } \ldots\end{array}$ & $\begin{array}{l}19 \\
-\end{array}$ & $\begin{array}{r}4 \\
-\end{array}$ & $\begin{array}{l}23 \\
-\end{array}$ & $\begin{array}{l}10 \\
-\end{array}$ & $\begin{array}{r}25 \\
6\end{array}$ & $\begin{array}{c}36 * \\
6\end{array}$ \\
\hline Total & 19 & 4 & 23 & 10 & 31 & $42 * t$ \\
\hline
\end{tabular}

* One patient died before dialysis.

* One patient died before dialysis.
+ Including seven patients who were also treated by conventional cannulation.

Excluding the six patients on the intermittent haemodialysis programme, 36 patients had shunts inserted and 113 dialyses were performed (mean 3.2).

* Consultant Urological Surgeon, the General Infirmary at Leeds. tConsultant in Clinical Renal Physiology, the General Infirmary at Leeds. 


\section{Cost, Time, and Convenience}

The Scribner shunt is not prohibitively expensive. There is an initial capital outlay of approximately $£ 65$ for equipment for making the U-tubes and for two special pairs of pliers used for crimping the rings of the shunt and cutting the extension tubes. All parts of the shunt itself are now made in Britain and each complete shunt costs $£ 6$ 12s. This cost is very small in comparison with the total cost of treating a patient with acute renal failure. For long-term intermittent haemodialysis we prefer to use American cannulae, but for short-term dialysis of patients with acute renal failure those of British manufacture ${ }^{1}$ have been completely satisfactory.

Operating-time is saved by the use of the Scribner shunt when a patient is dialysed more than twice. With conventional cannulation new cannulae have to be inserted before and removed after each dialysis; when a Scribner shunt has been inserted, connexion to and disconnexion from the dialyser is a quick procedure. The avoidance of repeated cannulation contributes much to the patient's comfort and well-being. Many of these ill patients used to dread dialysis because of the cannulation this entailed. Once a shunt has been inserted repeated dialysis causes them little discomfort.

One of the main advantages of using a shunt is the convenience of the method. If it is known that a patient will require dialysis within a few days, the shunt can be inserted at any time as an elective procedure. If conventional cannulae are being used it is normally only practicable to insert them immediately before each dialysis.

When useful blood-vessels are scarce the Scribner shunt is the best method of preserving those that remain.

\section{Safety}

Once a shunt has been inserted, the frequency and duration of dialysis can be carefully planned to suit the need of each individual patient. If conventional cannulae are inserted there is a tendency to dialyse for the maximum time to delay the next dialysis as long as possible. This can be dangerous for the following reason. During dialysis urea is removed more quickly from the blood than from the cerebrospinal fluid owing to slow diffusion of urea across the blood-cerebrospinal fluid barrier (Kennedy, Linton, and Eaton, 1962). Because of this, if a severely uraemic patient is dialysed too rapidly or too long, especially on a dialyser of large surface area, cerebral oedema occurs and the patient may suddenly have a convulsion and then die within a few minutes in spite of treatment. This is avoided by dialysing such patients slowly and only for a short time initially ; even so, there is still some advantage in increasing the concentration of glucose in the dialysing fluid as suggested by Kennedy, Linton, Luke, Renfrew, and Dinwoodie (1964). Several hours later, when an equilibrium has again been reached between the cerebrospinal fluid and the blood, the patient can be dialysed once more, and now it is safe to dialyse faster and for longer. If a shunt is in situ dialysis can then be repeated easily as often as necessary.

\section{Technique}

The method of inserting the shunt was described by Hegstrom, Quinton, Dillard, Cole, and Scribner (1961). This method was used, but the following modifications have been found useful.

Marking.-Before operation it was useful to mark on the skin of the patient the proposed sites of the subcutaneous

${ }^{1}$ British suppliers :-Stabilizers: C. F. Thackray, Park Street, Leeds 1. Silastic tubes: Esco Rubber, Seal Street, London E.8. Cannulae and extension tubes: Lusterlite Products Ltd., Devon Road, Leeds loops of the shunt, the points at which these loops would emerge from the skin, and the proposed incisions (Fig. 3). This ensured that the two loops did not encroach upon each other, that adequate freeing of the distal skin flaps was carried

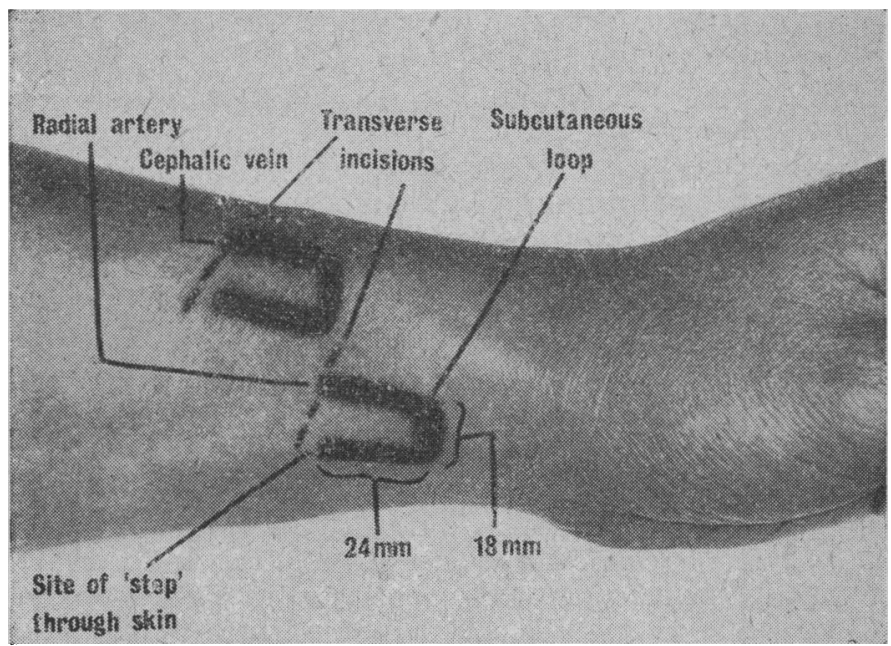

FIG. 3.-Pre-operative skin-marking.

out, and that the points where the tubes emerged through the skin were accurately sited (after the original incisions these positions may be distorted).

Incisions.-Transverse instead of the longitudinal incisions originally described were used. These incisions provided adequate exposure, healed better (as they lay in Langer's lines), and were thought to reduce the occurrence of extension of the subcutaneous tube.

Distal Skin Flap.-The distal pocket to receive the subcutaneous loop was fashioned by carrying the original incision

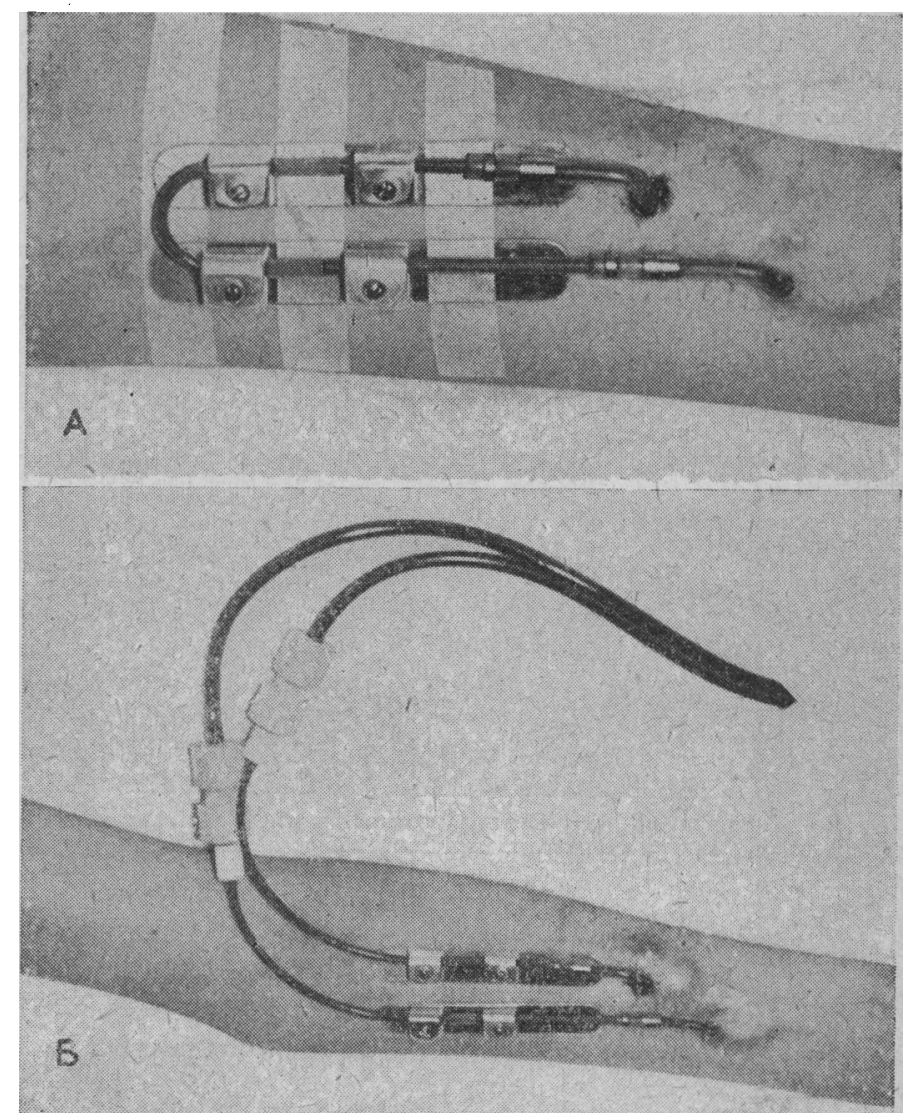

FIG. 4.-New stabilizers. A, U-tube fixed in position. B, Patient connected to the dialyser. 
down to the deep fascia, and by freeing the skin and superficial fascia from the deep fascia in this plane by blunt dissection with the finger. This procedure is quick, does not cause much bleeding, and does not devitalize the skin. It is easy to produce a pocket large enough for the subcutaneous loop to lie in it without distortion; its adequacy may be checked with a spare silastic tube.

Papaverine.-A few drops of papaverine $2.5 \%$ were placed on the artery after it had been mobilized, and in some cases a retrograde injection of papaverine was also made into its lumen after distal occlusion. This produced maximal dilatation within a few minutes so that the cannula could be inserted casily and without causing trauma to the vessel.

Stabilizers.-Special stabilizers were devised (Fig. 4) to perform the dual functions of holding the shunt fixed to the limb and holding the U-tube or connectors to the dialyser fixed to the extension tubes. These stabilizers proved extremely satisfactory and were preferable to the small pieces of adhesive strapping previously used to hold together the teflon tubes.

Antibiotics.-These patients received a course of a prophylactic antibiotic (cloxacillin sodium salt $250 \mathrm{mg}$. six-hourly for five days); the dressings were impregnated with chlorhexidine 1 in 2,000 in spirit. Wound infection was not encountered, and swabs from the points of emergence of the tubes have been sterile.

\section{Complications}

Clotting.-The commonest complication was clotting of the shunt. Six shunts clotted within the first three days ; in three cases this was thought to have been associated with a clotting tendency due to a recent splenectomy; in others it was due to inadequate venous "run-off," particularly when previous transfusions had caused thrombophlebitis. In three patients clatting occurred when renal function was returning. Eight shumts were cleared by removing the clot with suction followed by forcible irrigation with saline containing heparin. In two shunts no further clotting occurred.

Venous Stenosis.-Two shunts clotted repeatedly. This was shown on angiography to be due to stenosis of the vein

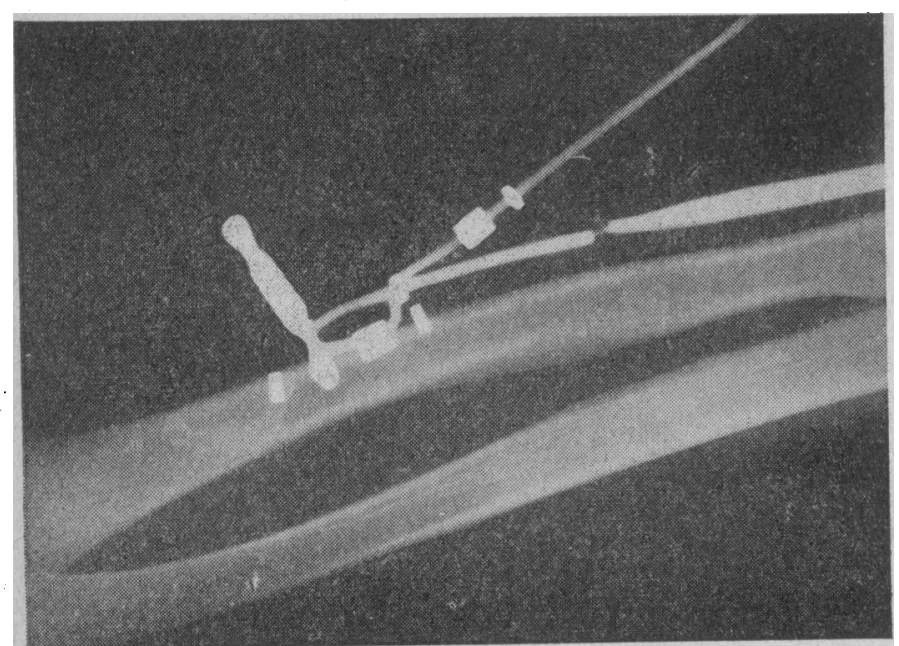

FIG. 5.-Venogram showing stenosis proximal to the tip of the cannula after prolonged intermittent haemodialysis. just beyond the tip of the cannula (Fig. 5). The venous cannula was therefore reinserted in the dilated vein proximal to the stenosis.

Extrusion of the Tube.-In two patients the arterial subcutaneous loop eroded through the skin. This may have been due to devitalization of the skin produced by the continuous pulsation of the tubing. In one a longitudinal incision had been made for the insertion of the shunt which extruded through the scar. Both patients were successfully treated by a secondary operation to bury the loop. In two patients an indolent ulcer formed over a crimp ring.

Thrombophlebitis.-One patient with a shunt in her leg developed thrombophlebitis in the saphenous vein. This was successfully treated by anticoagulant and antibiotic therapy.

Bleeding from the Shunt.-No complications due to bleeding from the intact shunt were encountered, in spite of the fact that many shunts were used for dialysis with the patient fully heparinized immediately after insertion. In two patients an extension tube came out of the silastic tube. In another patient the U-tube became detached from the extension tube (this was before the new stabilizers were used). A further patient, who was a respectable tramp, was found in a deserted house hanging by his heels from a hole in a ceiling. II had apparently been in this unusual position for nine hours and subsequently developed acute renal failure. He was dialysed four times before his renal function returned. He must have disagreed with this treatment, for he then pulled off his extension tube. The bleeding in all these patients was stopped quickly by an alert nursing staff by applying a Diefenbach clamp to the silastic tubing. Such a clamp is always kept attached to the bandaging. Such alarming occurrences are now prevented by fixing the U-tube to the extension tube with the new stabilizers and by using two crimp rings to fix the extension tubes to the silastic tubing. Suicide, however, will always be possible.

\section{Summary}

Experience with the Scribner shunt over the past year is reviewed and the advantages of the method over repeated cannulation for patients needing more than one haemodialysis are emphasized.

Complications likely to arise with the method are discussed. To minimize them modifications have been made in the mounting of the shunt and in the method of insertion which are described.

Fig. 1 is reproduced by kind permission of the editor of the Proceedings of the European Dialysis and Transplant Association, 1964.

\section{REFERENCES}

Chisholm, G. D. (1961). Brit. med. f., 2, 30.

Hegstrom, R. M., Quinton, W. E., Dillard, D. H., Cole, J. J., and Scribner, B. H. (1961). Trans. Amer. Soc. artif. intern. Organs, 7 , 47.

Kennedy, A. C., Linton, A. L., and Eaton, J. C. (1962) Lancet, 1, 410. Luke, R. G., Renfrew, S., and Dinwoodie, A. (1964). Ibid., 1,790 .

Quinton, W. E., Dillard, D. H., Cole, J. J., and Scribner, B. H. (1962). Trans. Amer. Soc. artif. intern. Organs, 8, 236. 